\title{
Stress-Strain Curves of Nafion Membranes in Acid and Salt Forms
}

\author{
Yoshio Kawano \\ Instituto de Química, USP
}

\author{
Yanqia Wang, Richard A. Palmer \\ Department of Chemistry, Duke University
}

\section{Steve R. Aubuchon}

\section{T. A. Instruments Inc.}

\begin{abstract}
Nafion membranes have been studied using dynamic mechanical analysis in the controlled force mode and clamp of tension film measurements for as received commercial Nafion membranes with different solvent contents and with different cations $\left(\mathrm{Li}^{+}, \mathrm{Na}^{+}, \mathrm{K}^{+}, \mathrm{Rb}^{+}\right.$and $\left.\mathrm{Cs}^{+}\right)$. In comparison with as-received Nafion membranes, the initial slope of the stress-strain curves decreases with increasing water contents in the Nafion membrane and also with the addition of methanol, ethanol and ethanol/ water $(50 / 50 \%, \mathrm{v} / \mathrm{v})$ mixture. The initial slope decreases also with increasing temperatures. On the other hand, the initial slope increases when the cation is replaced, in the following order: $\mathrm{Li}^{+}, \mathrm{Na}^{+}, \mathrm{K}^{+}$, $\mathrm{Cs}^{+}$and $\mathrm{Rb}^{+}$. Nafion in salt form normally shows an increase in the initial slope from room temperature up to approximately $90^{\circ} \mathrm{C}$, after which the slope decreases with increasing temperatures.
\end{abstract}

Keywords: Nafion, Stress-strain, DMA.

\section{Introduction}

Nafion ${ }^{\circledR}$ is a trade name of a perfluorosulfonate ionomer from E.I. Du Pont de Nemours \& Co. Inc., used extensively as a cation exchange membrane in electrochemical applications, including chloralkali cells $^{[1]}$, fuel cells ${ }^{[2]}$, water electrolysers ${ }^{[3]}$ and as polymer modified electrodes ${ }^{[4,5]}$. Nafion membrane consists of a polytetrafluoroethylene (PTFE) backbone and perfluorinated pendant side-chains terminated by sulfonic groups $-\mathrm{SO}_{3}{ }^{-} \mathrm{H}^{+}$(acid form), that can be easily substituted by $-\mathrm{SO}_{3}{ }^{-} \mathrm{M}^{+}$, where $\mathrm{M}^{+}$ represents exchangeable cations (salt form). These structures confer a high ionic conductivity, high mechanical, thermal and chemical stability. These properties are strongly influenced by the equivalent weight (EW), water content, nature of solvent, exchanged cations and temperature. Nafion is a commercially available membrane (Aldrich) and its molecular structure is well known.

Perfluorosulfonated ionomer membranes present a hydrophobic region, constituted by crystalline and amorphous domains formed by PTFE segments, and a hydrophilic region consisting of ionic domains formed by pendant side-chains of perfluorinated vinyl ethers terminated by ion-exchanged groups ${ }^{[6-9]}$. The ionic species are observed to aggregate and to form clusters that are interconnected by channels and distributed through the polymeric matrix. The water or solvents sorbed by the membrane are incorporated into the clusters and channels. These clusters swell according to the water content ${ }^{[9]}$ or the nature of solvents, changing the mechanical and chemical properties of membrane. The Nafion membrane also changes considerably its mechanical, thermal and chemical properties in cations-exchanged forms.

Autor para correspondência: Yoshio Kawano, USP/IQ, Departamento de Química Fundamental, Caixa Postal: 26077, CEP: 05513-970, São Paulo, SP. E-mail: ykawano@iq.usp.br 


$$
\begin{aligned}
& {\left[\left(\mathrm{CF}_{2}-\mathrm{CF}_{2}\right)_{\mathrm{n}} \mathrm{CF}_{2}-\mathrm{CF}\right]_{\mathrm{x}}}
\end{aligned}
$$

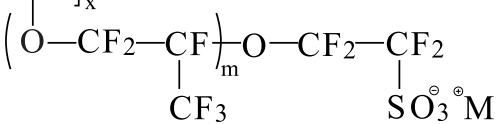

Figure 1. The molecular structure of Nafion membrane, where $\mathrm{n}=6.5$ to $13.5 ; \mathrm{m}=1,2, \ldots ; \mathrm{x}=200$ to $1000 ; \mathrm{M}^{+}$is the exchangeable cation. For Nafion 117 membrane EW 1100, $\mathrm{n}=6.5$ and $\mathrm{m}=1$.

In several applications, Nafion membranes are used as received commercial samples or treated at different conditions using the same thickness, so it will be interesting to know the mechanical properties of as received or modified Nafion membranes without changing the thickness.

This work investigates the stress-strain properties in tension at small strain of commercial Nafion membrane in acid form with different water content, and in salt forms with cation substitutions by means of dynamic mechanical analysis (DMA) measurements.

\section{Experimental}

A Nafion 117 membrane from Aldrich (27.467-4, Lot $\mathrm{N}^{\circ} \mathrm{TU} 08105 \mathrm{AU}$ ) with an EW of 1100 and 0.178 $\mathrm{mm}$ thick was used. Nafion acid $\left(\mathrm{Nafion}-\mathrm{H}^{+}\right)$sample was used as received, or soaked in distilled water for $24 \mathrm{~h}$, soaked in boiling water for $1 \mathrm{~h}$, soaked in methanol, ethanol or ethanol/water $(50 / 50 \%, \mathrm{v} / \mathrm{v})$ mixture for $24 \mathrm{~h}$. Nafion in salt forms were obtained by soaking Nafion- $\mathrm{H}^{+}$in $1 \mathrm{M}$ aqueous solutions of respective salt ( $\mathrm{LiCl}, \mathrm{NaCl}, \mathrm{KCl}, \mathrm{RbCl}$ and $\mathrm{CsCl}$ ) for $24 \mathrm{~h}$, at room temperature, rinsing in distilled water to remove the excess electrolyte, and wiping with filter paper. The dry Nafion membrane was dried using a vacuum oven at $70^{\circ} \mathrm{C}$ for $24 \mathrm{~h}$.

The stress-strain curves was obtained by the module of Dynamic Mechanical Analyzer (DMA), from T.A. Instruments, model 2980, controlled force mode, using the clamp of tension film for rectangular sample of length $\sim 25 \mathrm{~mm}$, width $\sim 6 \mathrm{~mm}$ and thickness of $0.178 \mathrm{~mm}$. The set of experimental parameters used was: preload force, $0.005 \mathrm{~N}$; isothermal, at $27^{\circ}, 60^{\circ}$, $90^{\circ}, 120^{\circ}, 150^{\circ}$ and $180^{\circ} \mathrm{C}$; soak time, $1.0 \mathrm{~min}$; force ramp rate, $0.500 \mathrm{~N} \cdot \mathrm{min}^{-1}$ and upper force limit, $18.00 \mathrm{~N}$.

\section{Results and Discussion}

The stress-strain curve for polymeric films is obtained by applying a tensile force at a uniform rate to a viscoelastic sample at a constant temperature. The stress-strain curve profiles are strongly influenced by the polymer structure, molecular weight, molecular weight distribution, chain branching, degree of crosslinking, chain orientation, extent of crystallization, crystal structure, size and shape of crystal, ionic interaction (for ionomers), processing conditions and temperature. The curve gives information about the Young modulus (slope at the origin), yield point, break point, elongation at break and the recovery behavior of polymeric films ${ }^{[11-13]}$. The early point of the stress-strain curve is usually of main interest from the standpoint of measuring viscoelastic properties of polymer.

Figure 2 shows the stress-strain curves of Nafion membrane as received, the membrane soaked in water for $24 \mathrm{~h}$ and membrane soaked in boiling water for $1 \mathrm{~h}$. The increase of water content decreases the initial slope of the curve, and increasing the degree of elongation the modulus reduces, particularly for the membrane soaked in water at its boiling temperature. The high water content swells the membrane and works as a plasticizer reducing the intermolecular forces, mainly the ionic interaction in ionomer increasing the degree of elongation. The stress-strain curve of Nafion membrane shows no yield point, and in the experimental conditions used, it is not observed the break point and also the elongation at break, so Nafion-acid membrane present a reasonably high tenacity and toughness (area under the stress-strain curve). No necking was observed in the experimental range of applied tension mode (small strain).

Figure 3 shows the stress-strain curves of as received Nafion membrane, Nafion soaked in

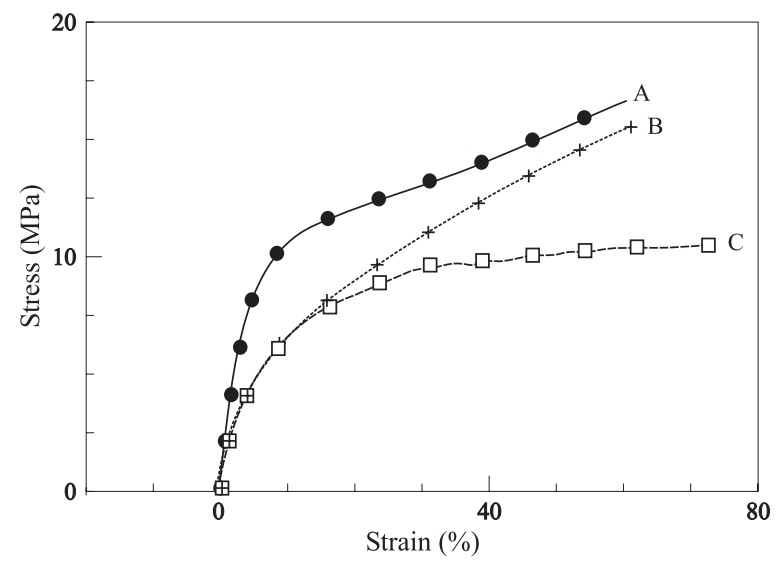

Figure 2. Stress-strain curves of Nafion membranes with different water content: (A) (- - ) as received; (B) (-+—) soaked in water for $24 \mathrm{~h}$; and $(\mathrm{C})(-\square-)$ soaked in boiling water for $1 \mathrm{~h}$. 
Table 1. Initial slope (MPa) of stress-strain curves of Nafion membrane with different solvents and salt forms at room temperature $\left(\sim 27^{\circ} \mathrm{C}\right)$.

\begin{tabular}{lc}
\multicolumn{1}{c}{ Sample } & Slope \\
\hline Nafion- $\mathrm{H}^{+}$as received & 2.00 \\
Nafion- $\mathrm{H}^{+}$in water 24h & 0.95 \\
Nafion- $\mathrm{H}^{+}$in boiling water 1h & 1.28 \\
Nafion- $\mathrm{H}^{+}$in methanol 24h & 1.12 \\
Nafion- $\mathrm{H}^{+}$in ethanol 24h & 0.50 \\
Nafion- $\mathrm{H}^{+}$in ethanol/water 24h & 1.35 \\
Nafion- $\mathrm{Li}^{+}$ & 1.62 \\
Nafion- $\mathrm{Na}^{+}$ & 2.49 \\
Nafion- $\mathrm{K}^{+}$ & 3.46 \\
Nafion- $\mathrm{Rb}^{+}$ & 5.58 \\
Nafion-Cs & 5.33 \\
\hline
\end{tabular}

methanol, in ethanol, and in mixture $(50 / 50 \%, \mathrm{v} / \mathrm{v})$ ethanol/water for $24 \mathrm{~h}$. The initial slope of the curve decreases in the order: as received Nafion, Nafion soaked in ethanol/water, in methanol, and in ethanol. Nafion soaked in ethanol/water mixture and in ethanol present a high degree of elongation with a lower modulus compared to the membrane soaked in water, indicating a lower intermolecular interaction, particularly the ionic interaction in membrane. The stress-strain curves behavior is similar for different solvents, which could be interpreted as a difference in the degree of swelling by different solvents.

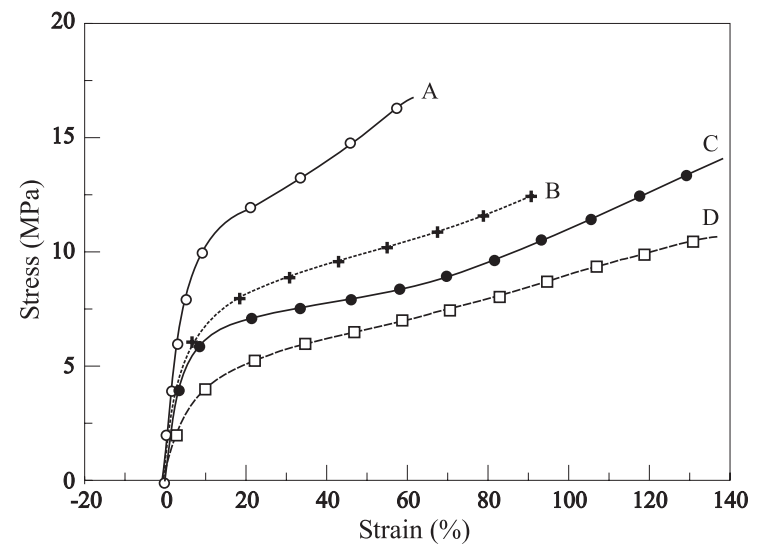

Figure 3. Stress-strain curves of Nafion membranes with different solvents: (A) (-O-) as received; (B) (-+ - ) soaked in methanol for $24 \mathrm{~h}$; (C) (- - ) soaked in ethanol/water for $24 \mathrm{~h}$; and (D) (- $\square)$ soaked in ethanol for $24 \mathrm{~h}$.

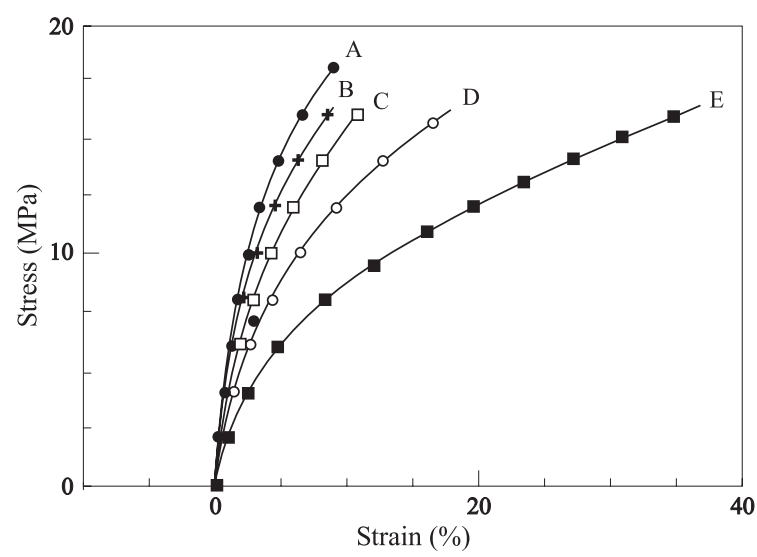

Figure 4. Stress-strain curves of Nafion membranes in different salt forms: (A) (-—-) Nafion- $\mathrm{Rb}^{+}$; (B) (-+-) Nafion-Cs ${ }^{+}$; (C) (一 Nafion- $\mathrm{K}^{+}$; (D) (—O-) Nafion-Na+ $\mathrm{Na}^{+}$and (E) (- - $)$Nafion- $\mathrm{Li}^{+}$.

Figure 4 shows the stress-strain curves of Nafion membrane substituted by $\mathrm{Li}^{+}, \mathrm{Na}^{+}, \mathrm{K}^{+}, \mathrm{Rb}^{+}$and $\mathrm{Cs}^{+}$ cations. It is observed that the initial slope increases in the order of $\mathrm{Li}^{+}, \mathrm{Na}^{+}, \mathrm{K}^{+}, \mathrm{Cs}^{+}$and $\mathrm{Rb}^{+}$cations, and the degree of elongation is lower compared to the as received Nafion. The stress-strain curves show an initial steep slope rising to a break or failure point at relatively low strain \%, a curve typical of a hard and brittle plastic. It is known that the water content in Nafion membrane decreases with increasing atomic radius of metal cations ${ }^{[14]}$. It is observed that the initial slope increases with increasing atomic radius of cations, except for $\mathrm{Cs}^{+}$cation (Table 1), showing the reduced plasticization effect of water and an increasing ionic interaction in Nafion membrane. Nafion membranes in salt forms present no swelling in salt solutions.

Some factors that make the polymer hard and brittle

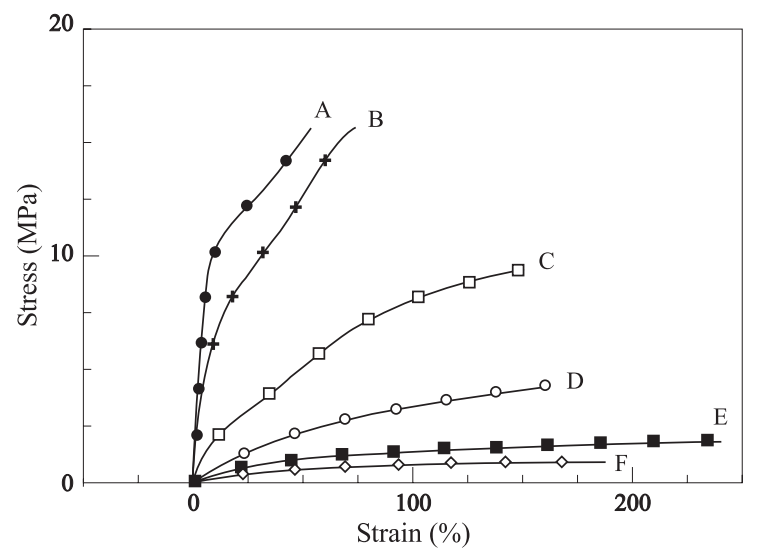

Figure 5. Stress-strain curves of as received Nafion membranes at different temperatures: (A) (-๑) room temperature; (B) $(-+-) 60^{\circ} \mathrm{C}$; (C)

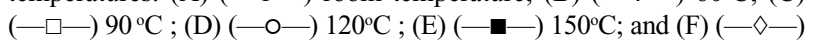
$180^{\circ} \mathrm{C}$ 
are the excessive cross-linking and the crystallization. Nafion membrane has the ionic cluster that works as a physical cross-linking, so increasing the ionic interaction in cluster it can reduce the chains mobility and the polymer becomes hard.

Increasing temperature normally causes a slow decrease in the Young modulus, as would be expected for increasing distances between the atoms at higher temperature.

Figure 5 shows the stress-strain curves of as received Nafion membrane at different temperatures $\left(27^{\circ}, 60^{\circ}, 90^{\circ}, 120^{\circ}, 150^{\circ}\right.$ and $\left.180^{\circ} \mathrm{C}\right)$. The initial slope of the curves decreases with increasing temperature, and the drop is large for temperatures higher than $90^{\circ} \mathrm{C}$. Only above this temperature the molecular motion is fast enough for the viscous flow to reduce the modulus to very low values, a behavior like plastic deformation. The stress-strain curve profile for Nafion at temperature higher than $60^{\circ} \mathrm{C}$ is similar to the curve of a soft and weak plastic. At temperatures higher than $150^{\circ} \mathrm{C}$, it is known that the clusters are disordered $^{[15]}$, the interaction forces between the polymer chains decrease and a low modulus produces a high degree of elongation, since Nafion presents a small degree of crystallinity.

Table 2 shows the data of initial slope of the curves at different temperatures.

Figure 6 shows the stress-strain curves of dry Nafion- $\mathrm{H}^{+}$membrane at different temperatures. The initial slope is high for the sample at room temperature, 60 and $90^{\circ} \mathrm{C}$, and decreases drastically for temperatures at 120,150 and $180^{\circ} \mathrm{C}$, as observed for as received Nafion membrane. The stress-strain curves profile at room temperature and $60^{\circ} \mathrm{C}$ is similar to hard and brittle plastic with a high modulus and low degree of

Table 2. Initial slope (MPa) of stress-strain curves of as receveid Nafion$\mathrm{H}^{+}$, dry Nafion- $\mathrm{H}^{+}$, Nafion-Na ${ }^{+}$and Nafion-Cs ${ }^{+}$salt forms and PTFE at different temperatures $\left({ }^{\circ} \mathrm{C}\right)$.

\begin{tabular}{ccccccc}
\hline $\begin{array}{c}\text { Sample/ } \\
\text { Temperature }\end{array}$ & $\mathbf{2 7}$ & $\mathbf{6 0}$ & $\mathbf{9 0}$ & $\mathbf{1 2 0}$ & $\mathbf{1 5 0}$ & $\mathbf{1 8 0}$ \\
\hline $\begin{array}{c}\text { Nafion- } \mathrm{H}^{+} \\
\text {as received }\end{array}$ & 2.10 & 1.47 & 0.44 & 0.05 & 0.03 & 0.02 \\
Nafion- $\mathrm{H}^{+}$dry & 2.10 & 1.76 & 0.80 & 0.13 & 0.04 & 0.02 \\
Nafion-Na $^{+}$ & 2.22 & 2.81 & 2.83 & 2.20 & 1.03 & 0.43 \\
Nafion-Cs $^{+}$ & 5.17 & 7.61 & 7.52 & 3.59 & 1.86 & 0.41 \\
PTFE & 2.46 & 2.08 & 1.01 & 0.88 & 0.44 & 0.43 \\
\hline
\end{tabular}

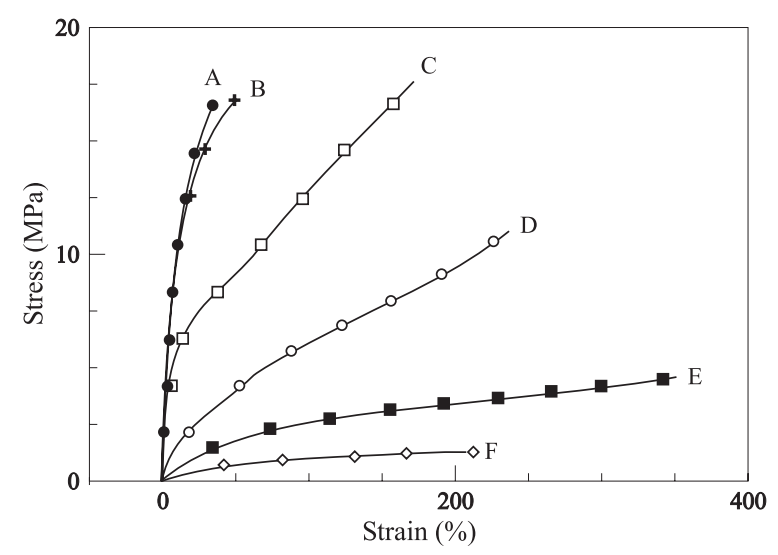

Figure 6. Stress-strain curves of dry Nafion- $\mathrm{H}^{+}$membranes at different temperatures: (A) (-—) room temperature; (B) $(-+-) 60^{\circ} \mathrm{C}$; (C)

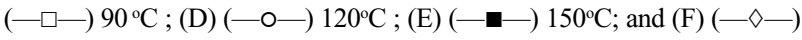
$180^{\circ} \mathrm{C}$

elongation. The absence of water in the cluster may increase the intermolecular forces and also the ionic interaction, and the increase of temperature will destroy the cluster structure and the polymeric chains will gain more mobility decreasing the modulus and increasing the degree of elongation.

Figure 7 shows stress-strain curves of Nafion membrane substituted by $\mathrm{Na}^{+}$cation, at different temperatures. The stress-strain curves behavior is very different compared to the curves of the as received Nafion- $\mathrm{H}^{+}$curves, particularly the curves of temperatures at 60 and $90^{\circ} \mathrm{C}$ that present the initial slope higher than that at room temperature. This behavior could be due to a small increase of crystallinity in the interphase between the amorphous and crystalline regions. The curves at temperature of 150 and $180^{\circ} \mathrm{C}$ show an initial slope lower than that at room

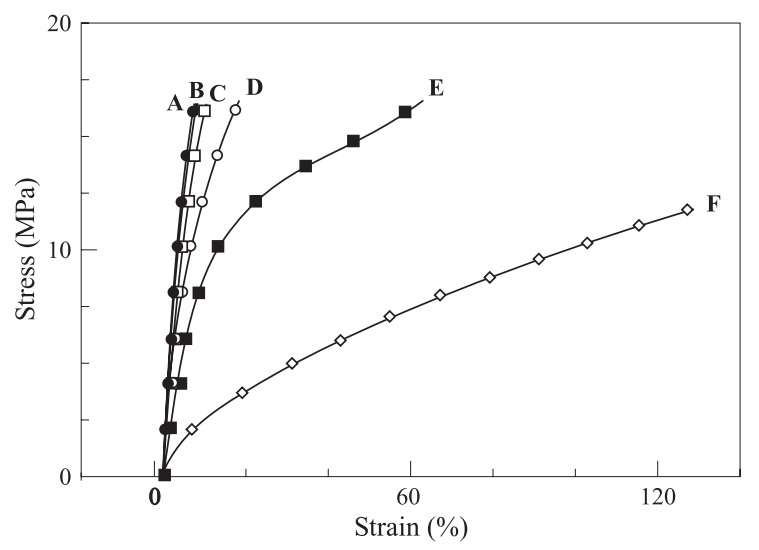

Figure 7. Stress-strain curves of Nafion- $\mathrm{Na}^{+}$membranes at different temperatures: (A) (-๑) room temperature; (B) $(-+-) 60^{\circ} \mathrm{C}$; (C)

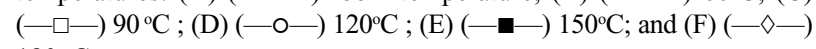
$180^{\circ} \mathrm{C}$ 


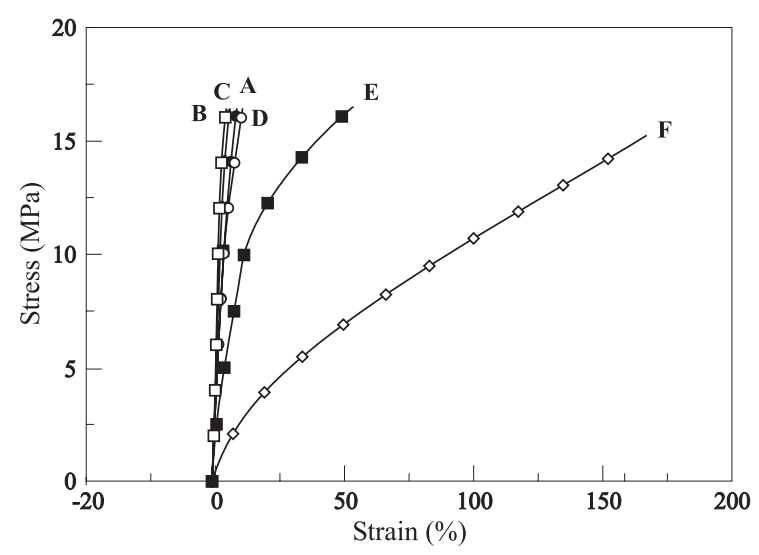

Figure 8. Stress-strain curves of Nafion- $\mathrm{Cs}^{+}$membranes at different temperatures: (A) (-- - ) room temperature; (B) (- -$) 60^{\circ} \mathrm{C}$; (C) $(-+-) 90^{\circ} \mathrm{C}$; (D) $(-\mathrm{O}-) 120^{\circ} \mathrm{C}$; (E) $(-\square-) 150^{\circ} \mathrm{C}$; and $(\mathrm{F})(-\diamond-)$ $180^{\circ} \mathrm{C}$

temperature. The curves at room temperature, 60,90 and $120^{\circ} \mathrm{C}$ show a behavior typical of hard and brittle polymer. For temperatures higher than $150^{\circ} \mathrm{C}$, the cluster structure is destroyed and the membrane presents high degree of elongation. The stress-strain curve profile is a result of reduced water content, which increases the intermolecular forces and the strong ionic interaction.

Figure 8 shows the stress-strain curves of Nafionmembrane substituted by $\mathrm{Cs}^{+}$cation at different temperatures. The stress-strain curves behavior is similar to that one observed for Nafion- $\mathrm{Na}^{+}$, but with the initial slope higher than that of $\mathrm{Na}^{+}$cation, and also lower degree of elongation, except for the slope and degree of elongation at $180^{\circ} \mathrm{C}$, which is approximately the same (Table 2). It is interesting to observe that in this case the high modulus is probably due to the high ionic interactions in the cluster, that at $180^{\circ} \mathrm{C}$ will be also reduced at the magnitude of the Nafion- $\mathrm{Na}^{+}$.

A similar behavior was observed for Nafion membrane substituted by other cations.

Figure 9 shows the stress-strain curves of PTFE film (thickness of $0.125 \mathrm{~mm}$ ) at different temperatures for the sake of comparison with the curves of Nafion membrane. The stress-strain curves show a decrease of initial slope with increasing temperature, and the modulus decreases drastically after a low degree of elongation. The applied stress causes the molecules to flow, so that the elongation increases remarkably at approximately constant stress, except for the curve at room temperature, where it is necessary a low rate increase of stress to produce an increase of strain percentage. The modulus of PTFE film is higher than

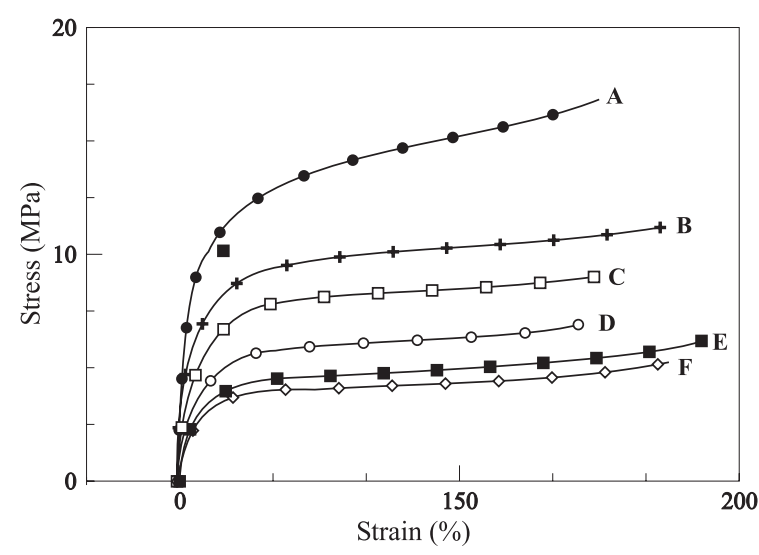

Figure 9. Stress-strain curves of PTFE films at different temperatures: (A) (-๑-) room temperature; (B) $(-+-) 60^{\circ} \mathrm{C}$; (C) $(-\square-) 90^{\circ} \mathrm{C}$; (D) $(-\mathrm{O}-) 120^{\circ} \mathrm{C}$; (E) $(-\mathbf{-}-) 150^{\circ} \mathrm{C}$; and $(\mathrm{F})(-\diamond-) 180^{\circ} \mathrm{C}$

that of as received Nafion at the same temperature because PTFE has a higher percentage of crystallinity (almost $100 \%)^{[16]}$ and higher melting temperature $\left(327^{\circ} \mathrm{C}\right.$ ) than Nafion membrane (a level close to $25 \%$ of crystallinity $)^{[16]}\left(\sim 230^{\circ} \mathrm{C}\right)$. The PTFE stress-strain curves at different temperatures show a similar profile at different temperatures due to the absence of water and ionic clusters, so the curves profiles are affected only by temperature dependence of intermolecular forces and the degree of crystallinity.

\section{Conclusion}

Nafion membrane with different treatments show drastic changes in the stress-strain curves profile. The initial slope decreases with increasing water content. It decreases in presence of solvents and with increasing temperature and increases with cation substitutions in the order: $\mathrm{Li}^{+}, \mathrm{Na}^{+}, \mathrm{K}^{+}, \mathrm{Cs}^{+}$and $\mathrm{Rb}^{+}$. The initial slope of Nafion salt forms normally increases until $90^{\circ} \mathrm{C}$ and then decreases with increasing temperature. The stress-strain curves shows a profile similar to a hard and brittle plastic for cation susbtitutions.

Both the stress-strain curve analysis and interpretation are challenging because the results depend upon several factors that are not yet well understood.

\section{Acknowledgements}

The authors are gratefully acknowledged to Dr. Chase Bruce from Du Pont, for the kind donation of Nafion sample. Y.K. thanks to FAPESP (99/10289-9) for a Post-Doctor fellowship at Duke University. 


\section{References}

1. Heitner-Wirguin, C. - J. Membr. Sci., 120, 1 (1996).

2. Okada, T.; Xie, G.; Gorseth, O.; Kjelstrup, S.; Nakamura, N. \& Arimura, T. - Electrochim. Acta, 43(24) 3741 (1998).

3. Okada, T.; Nakamura, N.; Yuasa, M. \& Sekine, I. - J. Electrochem. Soc., 144, 2744 (1997).

4. Rollet, A.-L/; Simonin, J.-P., Turq, P. - Phys. Chem. Chem. Phys., 2, 1029 (2000).

5. Okada, T.; Moller-Holst, S.; Gorseth, O. \& Kjelstrup, S. - J. Electroanal. Chem., 442, 137 (1998).

6. Rivin, D.; Kendrick, C.E.; Gibson, P.V. \& Schneider, N. S.- Polymer, 42, 623 (2001).

7. McLean, R.S.; Doyle, M. \& Sauer, B. B. - Macromolecules, 33, 6541 (2000).

8. Loppinet, BB. \& Gebel, G. - Langmuir, 14, 1977 (1998).

9. Gebel. G. - Polymer, 41, 5829 (2000).
10. Sperling, L.H. - "Introduction to Physical Polymer Science"John-Wiley, New York, chap. 9 (1986).

11. Freeman, W.J. - "Polymers: Polymer Characterization and Analysis" John Wiley, New York, p. 20-22 (1990).

12. Eisenberg, A. \& Kim, J.-S., "Introduction to Ionomers", John-Wiley, New York, (1998)

13. Hatakeyama T. \& Quinn, F.X. - "Thermal Analysis, Fundamentals and Applications to Polymer Science" $2^{\text {nd }}$ Ed., John-Wiley, New York, chap. 6 (1999).

14. Xie, G; Okada, T \& Arimura, T - Z. Physikal. Chemie Bd 205, p. 113 (1998).

15. de Almeida, S.H. \& Kawano, Y. - J. Thermal Analysis and Calorim., 58, p. 569 (1999).

16 Gruer, A.; Régis, A.; Schmatko, T. \& Colomban Vibrational Spectrosc. 26, 215 (2001).

Recebido: $15 / 08 / 01$

Aprovado: 20/04/02 